\title{
LAS IMBRICACIONES POLÍTICAS ENTRE LA PARTICIPACIÓN CIUDADANA E INTERNET
}

JORGE CASTELLANOS CLARAMUNT 
SUMARIO

1. INTERNET Y PARTICIPACIÓN CIUDADANA. 2. REDES SOCIALES Y PARTICIPACIÓN CIUDADANA. 3. E-DEMOCRACIA, ¿PROGRESO DEMOCRÁTICO? 4. REFLEXIONES SOBRE EL VOTO ELECTRÓNICO 


\title{
LAS IMBRICACIONES POLÍTICAS ENTRE LA PARTICIPACIÓN CIUDADANA E INTERNET
}

\author{
JORGE CASTELLANOS CLARAMUNT \\ Profesor contratado predoctoral (FPU) \\ Departamento de Filosofía del Derecho y Política \\ Universitat de València
}

\section{INTERNET Y PARTICIPACIÓN CIUDADANA}

Robert Dahl sostiene que una de las necesidades imperativas de los países democráticos consiste en potenciar las capacidades de los ciudadanos para que puedan implicarse inteligentemente en la vida política. El mero hecho de considerar que la potenciación de esas necesidades es de índole imperativa deja suficientemente claro que la propia democracia, para su supervivencia, debe adaptarse a los continuos avances técnicos que permitan su desarrollo. De ahí que Dahl concluya que no hay que prescindir de las instituciones existentes desde los siglos XIX y XX, pero sí que en los próximos años las instituciones más antiguas tienen que ser remozadas por nuevos medios destinados a la educación cívica, participación política, información y deliberación, que descansen de forma creativa en el conjunto de técnicas y tecnologías disponibles en el siglo $\mathrm{XXI}^{2}$. Y el paradigma de este desarrollo técnico que apunta Dahl es obviamente Internet ${ }^{3}$. Visto así, la influencia de Internet en la vida de las

1 Trabajo realizado gracias a la financiación del Ministerio de Ciencia, Innovación y Universidades (FPU014/02451). Departamento de Filosofía del Derecho y Política. Universitat de València. Facultad de Derecho. Campus dels Tarongers. Edificio Departamental Occidental. Avda. dels Tarongers s/n. 46071 VALENCIA. Email: jorge.castellanos@uv.es

2 Dahl, R. A.; La democracia: una guía para los ciudadanos (F. Vallespín, Trad.), Taurus, Madrid, 1999, pág. 37.

3 Las palabras de Dahl nos conducirían a una democracia participativa digital, la cual recibe también otros nombres como son democracia digital, democracia electrónica o e-democracia, nomenclatura esta última que es probablemente la más gráfica y clara de todas al denotar una influencia vital de las nuevas tecnologías en sinergia con la democracia. De ahí que hayamos escogido esta terminología en el título del presente capítulo. Para definirla diremos que la e-democracia viene a ser el modelo de democracia que propone el uso masivo y habitual de las nuevas tecnologías de la información 
personas puede redundar en mejoras democráticas ${ }^{4}$. Y aplicadas a cualquier campo de estudio que analicemos, las posibilidades que ofrece Internet son ilimitadas, por lo que el ámbito de estudio relativo a la participación ciudadana ${ }^{5}$ no iba a resultar una excepción. A través de Internet puede potenciarse, por ejemplo, la participación ciudadana en el debate previo a que las instituciones representativas adopten las decisiones correspondientes. En consecuencia, Internet puede ser contemplado como «un excelente medio de participación, de comunicación y por ende de influencia, entre los políticos y los ciudadanos $»^{6}$. De hecho Calle destaca el carácter reticular y agregador que pueden tener las nuevas tecnologías de información y comunicación y que facilita la creación de estructuras de participación muy concretas, como pueden ser «herramientas de difusión y de coordinación, ágoras de debate y comunidades de afinidad $»^{7}$. Pero la influencia de Internet en la vida política va mucho más allá de lo indicado, al punto que sostiene Anduiza que «es evidente que la participación política ya no puede ser entendida sin tener en cuenta la participación online» ${ }^{8}$.

«Internet es una extraordinaria herramienta adicional para la participación política, que permite estudiar, organizarse, intercambiar información, movilizarse, actuar, de una forma desconocida hasta que apareció, y que promete seguir ofreciéndonos innovaciones cada día»?

Desde finales del siglo XX se han venido produciendo importantes avances en el ámbito de los mecanismos participativos en Internet debido a su desarrollo y exten-

y la comunicación como ayuda o complemento en los procesos de participación democrática. En la misma línea Camisón Yagüe indica que «en un sentido amplio el concepto de e-democracia engloba el uso de las nuevas tecnologías de la información y las telecomunicaciones, fundamentalmente Internet, para la mejora de los procesos democráticos de toma de decisiones».

Camisón Yagüe, J. A.; "eDemocracia y control de principio de subsidiariedad en la Unión Europea: el IPEX”, en Noguera Fernández, A. (coord.), Crisis de la democracia y nuevas formas de participación, Tirant lo Blanch, Valencia, 2013, pág. 171.

${ }^{4}$ Cebrián Zazurca, E.; Deliberación en Internet: una propuesta de modelo de participación política, Fundación Manuel Giménez Abad de Estudios Parlamentarios y del Estado Autonómico, Zaragoza, 2012, pág. 28.

${ }^{5}$ La participación democrática digital es toda participación democrática que utiliza las nuevas tecnologías de la información y la comunicación, ya sea como canal de participación o simplemente como apoyo a un canal tradicional. La participación democrática digital es la acción política de la e-democracia.

${ }^{6}$ Pau i Vall, F.; "Democracia e Internet", Anuario de Derecho Constitucional y Parlamentario, 10, 1998, págs. 201-202.

7 Calle, Á.; La Transición inaplazable: salir de la crisis desde los nuevos sujetos políticos, Icaria, Barcelona, 2013, pág. 46.

8 Anduiza, E.; "Panacea", en Vallés, J. M. y Ballart, X. (eds.), Política para apolíticos: Contra la dimisión de los ciudadanos, $1^{a}$ ed., Ariel, Barcelona, 2012, pág. 132.

9 Arroyo, L.; “¿La ciberutopía era esto? Sofactivismo, tribalismo, nueva censura y trivialización del espacio público”, en Cotarelo, R. y Olmeda Gómez, J. A. (coords.), La democracia del siglo XXI: (política, medios de comunicación, internet y redes sociales), Centro de Estudios Políticos y Constitucionales, Madrid, 2014, pág. 144. 
sión ${ }^{10}$. Siguiendo en esta materia a Sànchez, de entre las experiencias más remarcables de potenciación de la participación a través de Internet en torno a las instituciones de gobierno cabe destacar las siguientes: MN E-Democracy (Minnesota, EEUU); Your Say (Reino Unido); y E-petitioner (Escocia). Respecto del primero, MN E-Democracy, hay que indicar que este proyecto comenzó a principios de la década de los noventa del siglo pasado y se puede considerar el decano de las experiencias de democracia electrónica. Se trata de una de las principales referencias en la participación política en la red. Minnesota E-democracy genera un foro específico de debates denominado MN-Politics a través de una lista de correo electrónico. Su objetivo es compartir la información sobre discusiones en materia de políticas públicas y de las cuestiones políticas de Minnesota. La principal virtud de esta experiencia es que con este foro se pretende cubrir un ámbito informativo que tenga utilidad y que sea participativo. En cuanto a Your Say subrayamos que es el espacio de participación que se puede encontrar en la página web del gobierno del Reino Unido, y que consiste en la creación de espacios de debate donde los ciudadanos pueden hacer llegar sus opiniones y sugerencias al gobierno. Así, en los inicios de la participación ciudadana por Internet observamos que una de las primeras medidas era fomentar espacios abiertos de debate, eliminando así las barreras de una participación amplia por motivos de espacio y tiempo, lo que evoca a la consideración de primordial de la participación ciudadana que desarrollaremos a lo largo del artículo: una participación ciudadana restringida a un ámbito, fundamentalmente el local, será, hasta en el ámbito tecnológico, la más eficiente y deseable. Y evolucionando sobre esa cuestión destacamos la tercera experiencia inicial de participación ciudadana en Internet a la que nos hemos referido que es E-petitioner, medida adoptada por el Parlamento de Escocia a inicios del año 2000 para crear un sistema electrónico de transmisión de peticiones desde la ciudadanía a la institución parlamentaria ${ }^{11}$.

Estas iniciativas pioneras sirvieron de ejemplo para potenciar la participación en los escenarios digitales en otros países, como por ejemplo Francia, que ha introducido mecanismos participativos en los que se establece una comunicación directa entre ciudadanos y parlamentarios como en su

«...plataforma oficial 'Parlamento y Ciudadanos', «Herramienta web» diseñada para «permitir a los parlamentarios y a los ciudadanos construir conjuntamente, paso a paso, propuestas de ley sólidas, reflexivas, compartidas y respaldadas». Diseñado para involucrar a los ciudadanos en legislación, basada en la idea de que votar no es suficiente para resumir su participación en la democracia, y que debemos ir más allá de la expresión organizada de cuerpos intermediarios y lobbies» ${ }^{12}$.

10 Castellanos Claramunt, J.; "Transhumanismo, algoritmos y nuevas tecnologías: avanzando en la desigualdad”, Ius et Scientia, Vol. 4, 2, 2018, págs. 120-131.

11 Sànchez, J.; "Internet como instrumento de participación”, en Font, J. (coord.), Ciudadanos y decisiones públicas, Ariel, Barcelona, 2001, págs. 146-148.

12 Arnaud, A.; La gouvernance. Un outil de participation, LGDJ-Lextenso éditions, Issy-lesMoulineaux, 2015, pág. 288. 
Ya en el escenario político español actual, dentro de las iniciativas participativas a nivel municipal destacan determinadas experiencias que se han puesto en marcha en grandes ciudades. Subirats las analiza positivamente, especialmente las realizadas en las dos grandes ciudades españolas, tanto Madrid como Barcelona:

«Las experiencias de «Madrid Decide» o «Decidim Barcelona» apuntan a nuevos formatos de participación mezclando participación convencional, vía entidades y reuniones presenciales, y participación digital de ciudadanos a título individual o de colectivos que no forzosamente pueden asistir u organizarse a tales efectos. En este sentido, es evidente que Internet ha logrado reducir de forma muy significativa los costes de la acción colectiva, permitiendo una redistribución de los recursos entre los actores y, en consecuencia, una alteración de las relaciones de poder. La red facilita el acceso al conocimiento, facilita compartir recursos y facilita la colaboración. Con ello la ciudadanía (y también los actores colectivos) cuentan con más recursos cognitivos y con una mayor capacidad de producción conjunta de conocimiento, de información y de estrategias de acción» ${ }^{13}$.

Dentro de las posibilidades que se suceden en el ámbito de Internet tal vez la que resulte más evidente es la relativa a la información. La información a través de Internet ha posibilitado cuestionar la centralidad de los grandes medios de comunicación de masas, dado que permite acceder a una información mucho más plural y ampliar el espacio de discusión y articulación política para las transformaciones sociales ${ }^{14}$. Ya hemos indicado que uno de los pilares básicos de la participación ciudadana es la información disponible para la ciudadanía de manera que este incremento exponencial de las posibilidades de informarse que conlleva Internet supone un salto cualitativo en todo proceso o mecanismo participativo. De hecho, Lenk sostiene que las tecnologías digitales mejoran la comunicación ya que implican un incremento en la información sobre un problema y su contexto, incluyendo métodos interactivos y multimedia y técnicas de realidad virtual. Del mismo modo facilitan procesos comunicacionales en los que incluyen formas asincrónicas y comunicaciones universales. También redunda en una mejor comunicación el hecho de que las tecnologías digitales estructuran mejor los debates y, en consecuencia, facilitan procesos de decisión ${ }^{15}$. En la misma línea de consideración positiva de las tecnologías de la información y la comunicación Peña López considera que las tecnologías de la información y la comunicación (en adelante TIC) «han eliminado de un plumazo tanto la escasez

13 Subirats, J.; El poder de lo próximo. Las virtudes del municipalismo, Los libros de la Catarata, Madrid, 2016, pág. 101.

14 Sanz, J. y Mateos, O.; 15-M. “Apuntes para el análisis de un movimiento en construcción”, Revista de Fomento Social, 263, 2011, págs. 517-544.

15 Lenk, K.; "Electronic support of citizen participation in planning processes", en Hague, B. N. y Loader, B. D. (eds.), Digital Democracy. Discourse and Decision Making in the Information Age, Rouyledge, Londres, 1999, pág. 88. 
de información como los costes de transacción asociados a su manejo» ${ }^{16}$. Del mismo modo, y con una estrecha relación con lo anterior, las TIC «han hecho casi irrelevante la cuestión de la movilidad a la hora, entre otras cosas, de informarse, debatir, negociar y, en definitiva, de expresar preferencias» ${ }^{17}$.

En todo caso, y antes de analizar en profundidad la cuestión de la participación ciudadana y las nuevas tecnologías conviene no soslayar una premisa básica y es que las tecnologías no son más que una herramienta, «un instrumento que tiene por objetivo constituirse en un apoyo que facilite la participación ciudadana» ${ }^{18}$. La tecnología no puede dar respuesta por sí misma a los problemas de la democracia, no es más que un medio al servicio de un fin ${ }^{19}$. Las tecnologías no pueden ser la clave ni el factor dominante, sino un mero elemento de apoyo y, por muy valioso que este sea, el referente principal debe ser siempre el ciudadano ${ }^{20}$. Así, Ramírez Nárdiz entiende estas nuevas tecnologías como un mecanismo para «mejorar el funcionamiento de la democracia representativa facilitando la introducción en ella de instrumentos de la democracia participativa» ${ }^{21}$.

La información debe de convertirse en un instrumento que logre la implicación de la ciudadanía en algo que se podría designar como compromiso virtual, superando una perspectiva meramente pasiva de la ciudadanía, ya que, como gráficamente se ha dicho, Internet no es por sí misma «un plus de democracia» ${ }^{22}$. Existe cierto sentimiento de apego inconsciente hacia todo lo que implique novedad, y la tecnología se nutre constantemente de esta situación. El profesor González De la Garza considera que «las nuevas tecnologías — por el solo hecho de ser «nuevas»-conducen a representaciones mentales que en su práctica totalidad no prometen sino expectativas positivas de progreso y bienestar» ${ }^{23}$. Pese a esta consideración, es obvio que la evolu-

16 Peña-López, I.; "Casual politics: del clickactivismo a los movimientos emergentes y el reconocimiento de patrones”, en Cotarelo, R. y Olmeda Gómez, J. A. (coords.), La democracia del siglo XXI: (politica, medios de comunicación, internet y redes sociales), Centro de Estudios Políticos y Constitucionales, Madrid, 2014, pág. 211.

17 Ibidem.

18 Ramírez Nárdiz, A.; Democracia participativa: la democracia participativa como profundización en la democracia, Tirant lo Blanch, Valencia, 2010, pág. 158.

19 Rubio Núñez, R.; “Las redes sociales en las administraciones ¿Periodo de pruebas?”, en Cotino Hueso, L. (ed.), Libertades de expresión e información en Internet y las redes sociales: ejercicio, amenazas y garantías, Servei de Publicacions de la Universitat de València, Valencia, 2011, pág. 151.

${ }^{20}$ Rivero Ortega, R. y Merino Estrada, V.; Innovación y gobiernos locales: Estrategias innovadoras de ayuntamientos y diputaciones en un contexto de crisis, $1^{a}$ ed., Instituto Nacional de Administración Pública, Madrid, 2014, pág. 94.

21 Ramírez Nárdiz, A.; Democracia participativa: la democracia participativa como profundización en la democracia, op. cit., pág. 158.

22 Lasagabaster, I.; "Las nuevas tecnologías y su aplicación para el progreso de la democracia”, en Barrat Esteve, J. y Fernández Riveira, R. M. (coords.), Derecho de sufragio y participación ciudadana a través de las nuevas tecnologías, $1^{\mathrm{a}}$ ed., Civitas, Cizur Menor Navarra, 2011, pág. 356.

${ }^{23}$ González De la Garza, L. M.; Voto electrónico por internet, constitución y riesgos para la democracia, Edisofer, Madrid, 2008, pág. 32. 
ción tecnológica de nuestras sociedades ha modificado sustancialmente muchos ámbitos de la vida social, cultural, económica y política, y en consecuencia también lo ha hecho con los medios de participación democrática. Pero lo primordial, lo básico, siempre será el hecho de participar, independientemente del modelo escogido, por lo que no hay que hacer una gradación en cuanto a los métodos por su importancia e innovación, sino trabajar para conseguir una participación lo más amplia, transversal e integradora posible. Por ello la aplicación de las nuevas tecnologías a la política y a la democracia tiene unas potencialidades enormes, y debe favorecerse su desarrollo en la medida en que amplía considerablemente tanto el número de ciudadanos que pueden interesarse en las cuestiones públicas y participar de ellas como la capacidad de adquirir información sobre cualquier asunto para, de ese modo, propiciar una participación no solo masiva, sino informada y responsable. Y es que lo que cambia el mundo digital no es tan solo la facilidad para transmitir y procesar información, sino la posibilidad de extender los mecanismos que estructuran la representación a cualquier ámbito, creando comunidades que sin esta comunicación no existirían nunca ${ }^{24}$. Por este motivo hay que elaborar estrategias que incidan en la disminución, y futura eliminación, de lo que se denomina brecha digital ${ }^{25} \mathrm{y}$, de este modo, conseguir un número más elevado de potenciales participantes en los asuntos públicos.

Para la mejora de la administración y el gobierno las nuevas tecnologías suponen un avance notable en muchos aspectos, pero especialmente en aquellos que implican un mayor grado de transparencia en la información y comunicación con la ciudadanía, de ahí la relevancia de introducir las innovaciones producidas por el uso de las TIC en el campo de la gestión pública, lo que se concreta en la administración electrónica, con todos sus componentes que incluyen también la transparencia electrónica y la rendición de cuentas digital; el gobierno electrónico; y la democracia digital ${ }^{26}$. Pero son muchas más las bondades que se predican de las TIC aplicadas a la política y a la participación ciudadana:

«El incremento que las TIC suponen en la libertad de expresión hace posible una comunicación multidireccional en la que cada usuario es receptor y emisor, favoreciendo así el debate político y de ideas. Las TIC constituyen un claro instrumento que puede servir para fortalecer la democracia representativa, al fomentar la participación

${ }^{24}$ Llauradó, J. M.; Democràcia digital: informació, participació, transparencia, Universitat de les Illes Balears, Palma de Mallorca, 2000, pág. 64.

${ }_{25}$ Cuando hablamos de brecha digital nos referimos al conjunto de desigualdades estructurales, culturales, educacionales o económicas que provocan que un sector de la ciudadanía se encuentre en inferioridad de oportunidades respecto al acceso y al uso de las tecnologías de la información y la comunicación. También recibe el nombre de fractura digital o división digital. La brecha digital principalmente se focaliza entre las generaciones más jóvenes y las más mayores, siendo estas últimas las que se encuentran más desfavorecidas. Otra fractura digital se produce en consonancia con las capacidades económicas, lo que agrava aún más la desigualdad social. El problema es importante ya que en situaciones extremas la brecha digital puede convertirse en un factor de exclusión social y política.

${ }^{26}$ Fundación Kaleidos; Proximidad, nuevas tecnologías y participación ciudadana en el ámbito local, Ediciones Trea, Gijón, 2010, pág. 63. 
política, la relación gobernantes-gobernados, el pluralismo político y social o el servicio al ciudadano de las diferentes Administraciones Públicas» ${ }^{27}$.

Sobre las TIC se ha escrito y profundizado mucho en cuanto a los avances que implican, pero también se ha dado la voz de alerta en base a la teoría de que deshumanizan las relaciones entre las personas y que dotan de frialdad a todo proceso, por supuesto también en el escenario de la participación ciudadana. De hecho Vilasau concluye que «el peligro de las redes sociales es que en ellas se pierden todos los matices y circunstancias característicos de la comunicación en el mundo offline (tono de voz, mirada, expresión, destinatario concreto) $»^{28}$. En todo caso, en este punto en el que estamos presentando las posibilidades de las TIC aplicadas a la profundización democrática no pretendemos rebatir el argumentario anexo a esta teoría, pero antes de exponer los mecanismos y posibilidades que brindan las TIC conviene subrayar algunos elementos positivos que a veces se pasan por alto. Uno de ellos es que gracias a estas tecnologías de la información y de la comunicación se generan nuevas relaciones sociales, así como se robustecen y reafirman las existentes. Pero es que además se pueden conducir de una manera muy positiva iniciativas de solidaridad por una circunstancia muy simple: al estar permanentemente conectados los unos con los otros pueden detectarse con mucha más facilidad y rapidez situaciones de carencia o necesidad existentes en cualquier ámbito. Esa relación mundial y global que permiten estas tecnologías implica un conocimiento muy rápido de estas circunstancias y pueden acometerse procesos participativos elaborados por los ciudadanos para solventarlos en el ámbito más cercano. Pero no problemática solo a nivel global, también tiene una incidencia a escala local puesto que la inmediatez en la detección de problemas o carencias próximas que a veces no se atisban por el contacto directo sí pueden descubrirse en base a criterios tecnológicos. Por ello las TIC ayudan a generar sentimientos de solidaridad y ayuda, y también sirven para canalizarlos de modo eficaz.

Como sostiene Ramírez Nárdiz, las Nuevas Tecnologías de la Información y la Comunicación (en adelante NTIC ${ }^{29}$ ) introducen mejoras técnicas que permiten optimizar los canales de información, comunicación, consulta, deliberación y participación — es decir, las distintas fases del proceso participativo- de los ciudadanos en la toma de decisiones públicas haciéndolos más inmediatos, sencillos y efectivos ${ }^{30}$.

27 Ríos Insúa, D.; La democracia electrónica, Lid, Madrid, 2008, pág. 162.

28 Vilasau, M.; "Privacidad, redes sociales y el factor humano”, en Rallo Lombarte, A. y Martínez Martínez, R., Derecho y redes sociales, $1^{\text {a }}$ ed., Civitas, Cizur Menor Navarra, 2010, pág. 61.

29 Ramírez Nárdiz define las NTIC como aquel conjunto de «innovaciones tecnológicas que facilitan la transmisión de la información de una manera rápida y segura, permitiendo con ello un desarrollo de los intercambios humanos tanto intelectuales como materiales. El ejemplo esencial de NTIC sería Internet». Ramírez Nárdiz, A.; Democracia participativa: la democracia participativa como profundización en la democracia, op. cit., pág. 153.

${ }^{30}$ Ibidem. 
Además de para mejorar las relaciones entre los ciudadanos, las TIC, como hemos apuntado ut supra, tienen una incidencia importante en la gestión pública ya que no solo implican la reducción de distancias físicas o simbólicas entre personas, sino también entre personas e instituciones. Ello viene de suyo puesto que al beneficiar de forma tan notable la posibilidad de transferir información y, especialmente, de forjar una excelente comunicación, hace que la Administración tenga a su disposición nuevos y mejores mecanismos de contacto con la ciudadanía. Con el uso de las TIC los ciudadanos pueden relacionarse de manera directa y sin coste con la Administración, por lo que las posibilidades de manifestar su opinión sobre alguna cuestión de índole municipal, su queja, denuncia, protesta o cualesquiera de sus variantes no acarrea un coste excesivo ni económico ni temporal, por lo que facilita que esta comunicación se produzca. Y no solo eso, por los mismos argumentos el coste de la respuesta disminuye considerablemente de modo que la Administración puede atender todas y cada una de las cuestiones planteadas de forma mucho más eficiente. De esta manera esa «devolución» será más adecuada y, con posterioridad, se podrá hacer un estudio del seguimiento de la cuestión planteada, su respuesta y la evaluación realizada al haber más posibilidades de establecer un contacto posterior. Desde este punto de vista las mejoras son obvias ya que permite un contacto directo y barato, una respuesta ágil y también sin coste, descontando la capacidad de seguir y evaluar cómo ha derivado el asunto en concreto y así obtener unas conclusiones óptimas para futuros casos similares. En conclusión, se establece un contacto directo, bidireccional, y con la posibilidad de análisis para llevar a cabo mejoras futuras, y todo ello además sin apenas coste.

Los mecanismos participativos existentes requieren de una información básica para que el ciudadano pueda comprender de forma integral aquella cuestión que se somete a debate y discusión. Y para que exista una información completa y que verdaderamente propicie una participación ciudadana efectiva y responsable, y no una mera acumulación de opiniones sin sostén informativo, las TIC ofrecen un avance considerable puesto que resulta posible, fácil y poco costoso proporcionar a los ciudadanos que van a participar en un determinado proceso participativo toda la documentación que se estime necesaria, desde la más básica y global a la más específica a través de contenidos digitales.

Por supuesto las TIC permiten ampliar la participación de forma exponencial ya que hacen factible que ciudadanos que habitualmente se encuentran excluidos puedan, efectivamente, participar. Y no solo nos referimos a una exclusión geográfica, que por supuesto también queda superada gracias a las nuevas tecnologías, sino a superar una exclusión personal. Las TIC dan la posibilidad de participar a personas que normalmente se encuentran alejadas de las cuestiones públicas y políticas en la medida en que sus condiciones personales implican una barrera infranqueable por circunstancias de timidez o dificultades con las habilidades sociales. Y ello sin contar a aquellos que padecen algún grado de discapacidad: 
«Internet colabora ayudando a la manifestación de la voluntad, permitiendo que las personas con dificultades de manifestación consientan exteriorizar su voluntad política y enterarse de las corrientes y programas de los partidos políticos, haciendo su expresión de la voluntad política más objetiva y, en fin, tomar conocimiento de la información que le permitirá ejercer su derecho-deber de ciudadanía» ${ }^{31}$.

Por ello las TIC derriban esos «muros» de naturaleza geográfica y/o personal, permiten interactuar y tomar parte en un mismo proceso a todo tipo de ciudadano debido a que su puesta en práctica determina que no es necesario que aquellos que participan en un proceso estén presentes, en ese momento, en el municipio en el que se desarrolla. El carácter remoto de la participación digital contribuye a acentuar el pluralismo de los participantes y, en consecuencia, enriquece la decisión adoptada. Por eso la aplicación de las TIC en el ámbito de la participación ciudadana supone una herramienta más para promover la tolerancia hacia la diferencia. De todo ello se extrae que la democracia digital tiene un efecto beneficioso para fomentar actitudes cívicas.

Además de la mejora que implican los mecanismos participativos en Internet en la superación de barreras físicas y temporales hay otro elemento sobre el que podemos incidir y es en la constancia en la participación. Rodotà denuncia que la democracia representativa y la directa adolecen del mismo problema respecto de la participación y es que esta resulta intermitente. Los ciudadanos son convocados por los poderes públicos en un periodo concreto, bien al elegir a sus representantes, bien al decidir sobre una determinada cuestión. Pero las posibilidades que se abren con las nuevas tecnologías, y con Internet en general, se amplifican al grado de que no tienen que ser convocadas ni acotadas a un periodo concreto las posibilidades participativas, sino que en todo momento y lugar pueden surgir nuevas iniciativas participativas significativas. Y esta cualidad va en la línea de lo que el propio Rodotà ha denominado «democracia continua», lo cual significa que la voz de los ciudadanos puede elevarse en cualquier momento y en cualquier lugar, convirtiéndose en parte del proceso político cotidiano ${ }^{32}$.

Es importante reflexionar sobre la nueva realidad de los tiempos y la profunda influencia que tienen las nuevas tecnologías en nuestra vida diaria. La democracia evoluciona al ritmo de las sociedades en las que se encuentra y no hay que perder de vista que también la relación de los ciudadanos y las tecnologías es susceptible de evolución. De ahí que al hablar de una democracia digital abordemos la cuestión de los mecanismos participativos que se suceden con el desarrollo tecnológico, sin olvidar el día a día del ciudadano. Sobre esta cuestión el profesor Lorenzo Cotino considera que «más allá incluso de los procesos formales e institucionales de participación,

31 David Araujo, L. A.; "Novas tecnologias e participação política das pessoas com deficiencia”, en Pajares Montolío, E. (ed.), Nuevas dimensiones de la participación política, Tirant lo Blanch, Valencia, 2015, pág. 272.

32 Rodotà, S.; Tecnopolitica. La democrazia e le nuove tecnologie della comunicazione, Laterza, Roma-Bari, 2004 . 
cualquier referencia a la participación y democracia electrónicas no puede escapar de la realidad del uso ciudadano y participativo de la red en la llamada web 2.0 o web

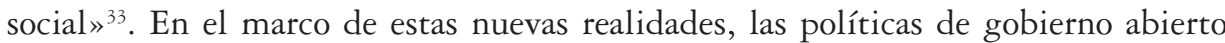
(participación, colaboración y transparencia) en el nivel de gobierno local intentan desarrollar una administración abierta, participada, cercana y eficaz que ahonde en la interrelación con la ciudadanía, instituyendo una comunicación permanente, transparente, bidireccional y en red, valiéndose, primordialmente, de las posibilidades de intervenir en la vida pública y en la toma de decisiones que las TIC suministran a todos los ciudadanos ${ }^{34}$.

Dentro de los diferentes niveles de participación que se estudian se suele subrayar que las TIC tienen una gran influencia respecto de la información y la comunicación, pero a veces no se destaca como debiera la radical mejora que producen las nuevas tecnologías en la fase de deliberación ${ }^{35}$. Sobre ello Iturbe Mach indica que la comunicación intensiva entre ciudadanos en un espacio virtual permite que la voluntad del demos, de la ciudadanía, la voluntad popular se conforme de un modo deliberativo ${ }^{36}$.

«Para que la ciudadanía pueda participar en procesos democráticos deliberativos, es necesario que haya información precisa y relevante; que haya cierto equilibrio entre las diversas posiciones sobre una misma controversia; que haya diversidad de opiniones; y que haya responsabilidad y criterio objetivo para que los ciudadanos participantes sopesen los diversos argumentos en sí mismos y con independencia de quién los emita. En potencia, Internet permite que esas condiciones se den ${ }^{37}$.

Realmente con la deliberación digital puede tenerse acceso a las opiniones de todos con mucha más profundidad que en los escenarios participativos presenciales que se seguían de forma tradicional. Es muy importante este dato porque además de eliminar la exclusión se deja constancia de las opiniones de todos y cada uno de los

33 Cotino Hueso, L.; “Tratamiento jurídico y normativo de la democracia, participación y transparencia electrónicas: presente y perspectivas”, en Barrat Esteve, J. y Fernández Riveira, R. M. (coords.), Derecho de sufragio y participación ciudadana a través de las nuevas tecnologías, $1^{\mathrm{a}}$ ed., Civitas, Cizur Menor Navarra, 2011, pág. 227.

34 Martín Cubas, J.; "Democracia participativa en los entornos locales”, en Noguera Tur, J. (coord.), La visión territorial y sostenible del desarrollo local: una perspectiva multidisciplinar, vol. 2 (Sociedad, gobierno, métodos, herramientas), 2016, págs. 35-56.

35 Como sostiene Hirschman, «una democracia adquiere legitimidad en la medida en que sus decisiones son el resultado de un proceso deliberativo abierto y totalmente desplegado que involucra a sus principales grupos, cuerpos constituidos y representantes».

Hirschman, A. O; Retoriche dell'intransigenza. Perversità, futilità, messa a repentaglio (trad. it. di G. Ferrara degli Uberti), Il Mulino, Bologna, 1991, pág. 171.

36 Iturbe Mach, A.; "Democracia, democracia electrónica y Parlamento Vasco”, en Barrat Esteve, J. y Fernández Riveira, R. M. (coords.), Derecho de sufragio y participación ciudadana a través de las nuevas tecnologías, $1^{a}$ ed., Civitas, Cizur Menor Navarra, 2011, pág. 268.

37 Arroyo, L.; “¿La ciberutopía era esto? Sofactivismo, tribalismo, nueva censura y trivialización del espacio público”, en Cotarelo, R. y Olmeda Gómez, J. A. (coords.), La democracia del siglo XXI: (politica, medios de comunicación, internet y redes sociales), Centro de Estudios Políticos y Constitucionales, Madrid, 2014., pág. 140. 
intervinientes. Ninguna voz se acalla entre todas. Todas pueden ser leídas en igualdad de condiciones. Este dato es valiosísimo puesto que no se producen interferencias en la discusión de los grupos, se elude el murmullo que impide la libre expresión de todos y evita que momentos de déficit de atención impidan valorar en su justa medida opiniones y visiones aportadas sobre un asunto en concreto que podrían quedar sin la consideración debida. No solo se aporta desde la perspectiva de cada uno sino que se deja constancia de ello. Se delibera en un concepto mucho más amplio puesto que no se desecha, por el motivo que sea, ninguna de las aportaciones. La comunicación no se ve afectada y puede volverse a puntos de entendimiento anteriores sin resquebrajar el proceso deliberativo. En consecuencia la deliberación digital aporta una característica fundamental y es que la hace flexible. Todos pueden participar, ser leídos, retomar los puntos de encuentro y avanzar en la discusión de una decisión o posición conjunta y consensuada. Si la actitud y predisposición son las adecuadas las posibilidades de la deliberación digital superan en mucho las de la deliberación tradicional. El salto de calidad es notable en cuanto a que no solo se eliminan barreras físicas, geográficas y personales, sino que añade el dato cualitativo de la flexibilidad temporal. Se puede retomar la discusión desde el punto deseado retrocediendo en la misma puesto que todos los que han participado han dejado constancia de sus aportaciones. La deliberación digital ordena cualquier mecanismo participativo y si lo que se pretende es llegar a puntos de conexión y a decisiones justas y colectivas este elemento resulta esencial. Esta es una de las grandes ventajas de las TIC a la hora de enriquecer la fase de deliberación y debate. Y como efecto de todo ello, el número de participantes en una deliberación online puede ser muy superior al de una presencial, sin perder por ello ni orden ni rigor.

\section{REDES SOCIALES Y PARTICIPACIÓN CIUDADANA}

Las redes sociales (en adelante RRSS) suponen un ejemplo de participación directa por parte del ciudadano. Constituyen un espacio de libertad, donde el individuo puede dejar su impronta y formar parte del grupo ${ }^{38}$. La influencia de las nuevas tecnologías de la información y la comunicación en la participación ciudadana es un fenómeno imparable y sin retorno. Y el paradigma de ello es la difusión que han alcanzado las RRSS, a las que Ortiz López define de manera amplia como «aquellos servicios de la sociedad de la información que ofrecen a los usuarios una plataforma de comunicación a través de Internet para que estos generen un perfil con sus datos personales, facilitando la creación de redes en base a criterios comunes y permitiendo

38 Ramón Fernández, F.; "La red social como ejemplo de participación: casos y cuestiones”, en Cotino Hueso, L. (ed.), Libertades de expresión e información en Internet y las redes sociales: ejercicio, amenazas y garantías, Servei de Publicacions de la Universitat de València, Valencia, 2011, pág. 171. 
la conexión con otros usuarios y su interacción» ${ }^{39}$. Por eso las RRSS son un potenciador sin parangón de la conectividad entre personas y, en consecuencia, del incremento exponencial de métodos para organizarse colectivamente y participar puesto que las redes cívicas «nacen con el objetivo declarado de fomentar la participación ciudadana, además de garantizar la transparencia y la simplificación» ${ }^{40}$. El profesor González De la Garza indica que «en redes como Facebook se generan diariamente 10.000 millones de mensajes, los usuarios comparten 350 millones de fotografías y vídeos y señalan con el icono «me gusta» 4.500 millones de páginas. Estas cifras son diarias y crecen día a día» ${ }^{41}$. Por su parte Arnaud considera que una de las principales críticas sobre la democracia representativa se basa en que producen una cierta exclusión de los ciudadanos de la vida política y que la existencia de las RRSS a través de Internet resulta un acercamiento entre la política y la vida cotidiana de las personas, de lo que concluye que gracias a ellas se produce un fortalecimiento de la soberanía popular ${ }^{42}$.

Siguiendo a Rubio Núñez, destacamos que las RRSS permiten que la Administración se relacione con los ciudadanos de manera transversal en cuatro ámbitos, a saber, la comunicación, la comunidad, la cooperación y la participación. Respecto de la comunicación, las RRSS nos ayudan a encontrar otras personas con intereses comunes y organizarnos en torno a comunidades, dando lugar a una posible cooperación, ya que ayudan a hacer cosas juntos, siendo el ámbito político el lugar más adecuado para esta confluencia de acciones, por lo que de suyo puede llegarse a un estrato de participación en base a las RRSS, puesto que nos ayudan a los ciudadanos a contribuir en la adopción de decisiones públicas ${ }^{43}$.

Sea como fuere, lo cierto es que la principal función de las RRSS en el ámbito político y participativo ha sido la de propiciar la interconectividad y la complementariedad relativa a la movilización en las calles. De este modo junto a la ocupación de espacios para realizar protestas, manifestar reivindicaciones o bien como muestra de organización de los ciudadanos frente a situaciones sobre las que no estaban de acuerdo el fenómeno de las RRSS ha devenido en esencial:

39 Ortiz López, P.; "Redes sociales: funcionamiento y tratamiento de información personal", en Rallo Lombarte, A. y Martínez Martínez, R., Derecho y redes sociales, $1^{\text {a }}$ ed., Civitas, Cizur Menor Navarra, 2010, pág. 24.

${ }^{40}$ Costanzo, P.; "Quale partecipazione politica attraverso le nuove tecnologie comunicative in Italia”, en Pajares Montolío, E. (ed.), Nuevas dimensiones de la participación política, Tirant lo Blanch, Valencia, 2015, pág. 200.

41 González De la Garza, L. M.; La crisis de la democracia representativa. Nuevas relaciones políticas entre democracia, populismo virtual, poderes privados y tecnocracia en la era de la propaganda electoral cognitiva virtual, el microtargeting y el big data, UNED, Revista de Derecho Político, 103, 2018, págs. 257-302.

42 Arnaud, A.; La gouvernance. Un outil de participation, op. cit., pág. 287.

43 Rubio Núñez, R.; "Las redes sociales en las administraciones ¿Periodo de pruebas?”, op. cit., pág. 156. 
«Los grandes nodos de información crecidos de forma descentralizada al calor de los acontecimientos y su popularidad son impresionantes. Lo que no hace sino corroborar el papel del uso masivo de Internet en la descentralizada red como soporte comunicador del fenómeno de protesta social en la calle» ${ }^{44}$.

Por ello, la presencia continua en redes sociales para organizar actos colectivos llega a tal calibre que se ha generado así una hibridación entre el espacio urbano y el ciberespacio, lo que Castells denomina el «espacio de la autonomía» ${ }^{45}$. Y es que la irrupción de las RRSS en la influencia política es creciente. Tenemos ejemplos muy notorios y claros en las carreras electorales de Barack Obama y Donald Trump en EEUU, en las que la movilización de votantes y de apoyos que se generó a través de Internet mediante las RRSS colaboró decisivamente en sus éxitos. También destaca el uso de Internet y las RRSS en Italia con el Movimento 5 Stelle (Movimiento 5 Estrellas, en adelante M5E), que ha construido buena parte de su discurso político contra los medios informativos y las oportunidades de Internet para llamar la atención, y captar simpatías y votos, puesto que las RRSS son ahora la puerta de entrada de la información $^{46}$.

Las redes sociales han devenido en un instrumento fundamental en procesos de organización ciudadana y, en consecuencia, en el impulso participativo. Siguiendo a Subirats podemos distinguir como rasgos característicos de estas nuevas formas de participación política desde abajo y con amplio uso de Internet y de las RRSS la radicalidad democrática, la colaboración, la conectividad, la presión e implementación y la glocalización ${ }^{47}$. Respecto de la radicalidad democrática lo más reseñable es que se fundamenta en un esquema de democracia que está desligado de las Administraciones

${ }^{44}$ Lacasta Zabalza, J. I.; Memoria colectiva, pluralismo y participación democrática, Tirant Humanidades, Valencia, 2013, págs. 213-214.

45 Castells, M.; Redes de indignación y esperanza, Alianza Editorial, Barcelona, 2013.

46 Hemos destacado el ejemplo de Obama porque supuso un antes y un después en el uso de las redes sociales e Internet en un proceso tan importante a nivel planetario como es la elección del Presidente de los Estados Unidos. Y también citamos a Donald Trump porque su uso de las RRSS ha supuesto un punto de inflexión en el modo de adaptar y adoptar estas tecnologías en el día a día de la política. Del mismo modo hemos destacado la irrupción del Movimento 5 Stelle en Italia puesto que el fenómeno social encabezado por Beppe Grillo es un punto de estudio ineludible si tratamos el tema de la participación ciudadana en base a los avances de Internet y las redes sociales. En todo caso los ejemplos que se han sucedido en los últimos años de protestas, quejas sociales y diversos fenómenos colectivos que abogan por una mayor y mejor participación de los ciudadanos en los asuntos públicos se han caracterizado por una conjunción destacable de estas peticiones y la utilización masiva de las redes sociales para propiciar la acción colectiva, por lo que sin pretensión de ser exhaustivos podemos citar a modo de ejemplo lo sucedido en España con el 15M, en Estados Unidos con la acción Occupy Wall Street, en México con el movimiento Yo soy 132, en Brasil con el movimiento Passe Libre, en Turquía con el Gezi Park, y la Revolución de los Paraguas en Hong Kong. Todas ellas son nuevas experiencias de movilización y de acción colectiva, que han ido más allá de los parámetros tradicionales, y en las que el papel de Internet y de las redes sociales ha sido muy relevante, permitiendo espacios de experimentación e innovación social.

47 Subirats, J.; El poder de lo próximo. Las virtudes del municipalismo, op. cit., págs. 98-102. 
Públicas (en adelante AAPP) y el mercado, se basa únicamente en la incorporación de intereses colectivos, por lo que prima el respeto a la diversidad y a la gestión de algo común. Evoca una democracia pura en la medida en que todos participan como iguales sin establecer diferencias ni gradaciones, lo cual se asemeja en sus esquemas a lo que encontramos en las RRSS. Todos crean su usuario de la red social en cuestión y se abren a la inmensidad de las intercomunicaciones que presentan estos ámbitos de comunicación. En cuanto a la colaboración, este elemento supone una característica obvia en los procesos participativos basados en Internet y las RRSS. No existe jerarquía por lo que se basan en procesos horizontales afirmados, en consecuencia, en la colaboración y la cooperación. Ante unas mismas preocupaciones, opiniones o realidades los ciudadanos se agrupan en base a criterios de colaboración. El tercer rasgo característico de estas iniciativas es la conectividad puesto que los ciudadanos se comunican directamente, sin intermediarios de ningún tipo. El concepto de colaboración unido a la radicalidad democrática de estas actividades lleva consigo la necesidad de una conectividad permanente entre todos los interesados y ese es, precisamente, el elemento definidor de las redes sociales, la constante y permanente capacidad de estar conectado con los demás. Obviamente esos procesos desde abajo y sustentados en la unión de los ciudadanos con respecto a un propósito concreto y auspiciados por la conectividad que facilitan las RRSS desemboca en un grupo cada vez más numeroso de personas que pretenden presionar a los representantes públicos para llevar a cabo las medidas objeto de su iniciativa. La presión ejercida será proporcional al número de ciudadanos que se hayan agregado al mecanismo participativo en cuestión. Y si la actividad realizada adquiere una dimensión adecuada, por el apoyo recibido y la organización dirigida a tal fin, es posible que se acaben implementando las alternativas planteadas como efecto de esa presión ejercida. Y esta presión ejercida vendrá determinada también por el último elemento que destacábamos que es el de la glocalización puesto que estas experiencias de innovación social actúan desde una lógica que combina la escala local con la global. Al pretender una gran repercusión, el fenómeno puede expandirse de lo local a lo global para potenciarlo y así extraer unas consecuencias más provechosas. La ilimitada capacidad de Internet y las RRSS de expandir circunstancias que en un primer momento son locales profundiza en la dimensión del mecanismo empleado y ayuda a presionar a los dirigentes para que tomen en consideración las acciones propuestas. Vendría a producirse así una relación directa entre aquello que se ha denominado «viralidad» e incidencia directa en la toma de decisiones ${ }^{48}$. Este dato es especial-

48 Hablamos de «viralidad» cuando un determinado contenido se difunde de una forma multitudinaria en Internet, principalmente a través de las redes sociales. Normalmente está asociado a un elemento visual como un vídeo o una fotografía, pero también puede darse con contenidos escritos. Lo principal del hecho es que el elemento en sí se expanda entre los participantes de una red social al punto de que a los que alcance ese contenido lo amplifiquen a su vez a sus contactos, produciéndose una transmisión en cadena difícilmente cuantificable. Si esta cuestión la relacionamos con el ámbito político la trascendencia de esa «viralidad» no puede ser prevista con facilidad ya que puede acometerse un cambio sustancial entre la ciudadanía sobre una cuestión fundamental, o bien tratarse de una campaña 
mente relevante en nuestro ámbito de estudio porque al referirnos a la participación ciudadana en relación a las instituciones locales puede deducirse que toda actuación va a ceñirse, única y exclusivamente, a la relación del ciudadano con la institución que le es más próxima, fundamentalmente el escenario municipal. Pero ello, sin dejar de ser cierto, no acota la cuestión del todo porque una situación que responda a la complejidad local puede magnificarse en grado sumo por la influencia de las RRSS. El altavoz de Internet sobre una cuestión local y puntual es imposible de cuantificar, de modo que pese a que tratemos relaciones políticas de ciudadanos con instituciones locales concretas, la problemática política y social puede llegar a cualquier parte del mundo, sin dejar, no obstante, de ser una cuestión local. Por tanto, al tener las RRSS tal potencial y capacidad para poner en el primer plano cuestiones de toda índole, deben tenerse en cuenta, también, para estudiar los asuntos locales. Y esto observando la cuestión desde los parámetros de la ciudadanía, pero también puede darse desde la perspectiva de los representantes políticos:

«En ningún caso se puede perder de vista el poder de las redes en nuestro tiempo. No solo permiten poner en común experiencias a las personas privadas; también pueden servir para el mismo propósito entre responsables públicos, sin descartar la participación directa de los ciudadanos en estos foros, porque la innovación no será satisfactoria si no hace suyas las propuestas de los destinatarios de sus ventajas: los usuarios de los servicios públicos y, en general, los ciudadanos» ${ }^{49}$.

\section{E-DEMOCRACIA, ¿PROGRESO DEMOCRÁTICO?}

Hemos afirmado que la influencia de las nuevas tecnologías de la información y la comunicación en la participación ciudadana es un fenómeno progresivo y sin retorno. $\mathrm{Y}$ es que «el avance de Internet es imparable tanto en la calidad técnica como en la evolución de los servicios y prestaciones para los usuarios» ${ }^{50}$. Sobre esta cuestión puede alcanzarse un consenso general y tanto los ciudadanos como las Administraciones son plenamente conscientes de ello. Hemos destacado las posibilidades participativas que se derivan de un avance tecnológico como el que se ha producido en los últimos tiempos y que aplicadas a mecanismos participativos llevarían, de suyo, a unas sociedades más democráticas y participativas. A colación podemos traer la reflexión de Arnaud cuando sostiene que la práctica de la «democracia electrónica» hace posible desarrollar iniciativas de la democracia participativa y que es necesario contar

u ola de opinión de corto recorrido. Dependerá del caso en concreto que se analice, pero no cabe infravalorar las posibilidades de cambio social y político que pueden provocar tales hechos.

49 Rivero Ortega, R. y Merino Estrada, V.; Innovación y gobiernos locales: Estrategias innovadoras de ayuntamientos y diputaciones en un contexto de crisis, op. cit., pág. 45.

${ }^{50}$ Martínez Martínez, R.; "Protección de datos personales y redes sociales: un cambio de paradigma”, en A. Rallo Lombarte y R. Martínez Martínez, Derecho y redes sociales, $1^{a}$ ed., Civitas, Cizur Menor Navarra, 2010, págs. 83-84. 
con el uso de las TIC y las NTIC en los procesos de eParticipación a nivel local ${ }^{51}$. Ahora bien, ¿por qué esto no tiene una plasmación efectiva y directa en nuestro día a día? Si se aboga desde todas las perspectivas sociales posibles por una más y mejor democracia y convenimos en que la mejora tecnológica aproxima al ciudadano a la deliberación y toma de decisiones habrá que preguntarse el motivo por el que estas realidades efectivas, que en casi cualquier sector de la vida diaria de los ciudadanos se actualizan y añaden con relativa naturalidad, no se llevan a cabo de la misma forma en el ámbito político.

Una de las cuestiones que se plantean es la falta de adaptación de las Administraciones a la realidad social actual ya que «el concepto de e-government lamentablemente no suele incluir la participación política sino que se entiende habitualmente como un sistema de mejorar y hacer eficiente la actuación administrativa ${ }^{52}$. Esta sería una de las críticas al modo en que se asume la mejora tecnológica en el ámbito participativo puesto que las AAPP tienen una tendencia generalizada a utilizar Internet únicamente como una nueva herramienta para seguir actuando como ya hacían, pero de forma más eficiente. Es decir, la utilización de las nuevas tecnologías pasaría por hacer un uso de Internet basado en la comunicación unidireccional, en poner en conocimiento del ciudadano aquellas cuestiones que le interesan, pero cercenando cualquier posibilidad de comunicación bidireccional o entre los propios ciudadanos en red como consecuencia de la comunicación institucional.

«Las nuevas tecnologías son concebidas por los partidos como un canal unidireccional de comunicación pensado para funcionar tan solo desde ellos hacia los ciudadanos y no a la inversa; las leyes de transparencia han convertido, asimismo, en obligaciones jurídicas medidas que ya deberían haber sido efectivas como meros deberes éticos, amén de que su eficacia continúa dependiendo en exceso de la voluntad de sus ejecutores» ${ }^{53}$.

En esta línea Ríos Insúa manifiesta que «las aplicaciones, potenciales o reales, de las TIC a la democracia son ciertamente muy numerosas. Algunas de estas posibilidades van en la línea de hacer más eficientes los procedimientos políticos tradicionales ${ }^{54}$. En consecuencia encontramos pocos ejemplos de gobiernos locales que profundicen en la mejora democrática en base a las nuevas tecnologías y que fomenten una mejor forma de organizarse o de producir políticas públicas. Sobre ello afirma el profesor Cerrillo que cada vez más ciudadanos acceden a la información del sector público a través de servicios prestados por otros ciudadanos, en vez de sitios Web u

51 Arnaud, A.; La gouvernance. Un outil de participation, op. cit., pág. 291.

52 Corredoira Alfonso, L., y Cotino Hueso, L.; Libertad de expresión e información en Internet: Amenazas y protección de los derechos personales, Centro de Estudios Políticos y Constitucionales, Madrid, 2013, pág. 30.

53 Garrorena, A.; "Democracia, participación y representación. La crisis actual de la democracia representativa”, en Asociación de Constitucionalistas de España, Martín de la Vega, A., y Cascajo Castro, J. L. (coords.), Participación, representación y democracia: XII congreso de la asociación de constitucionalistas de España, Tirant lo Blanch, Valencia, 2016, pág. 76.

54 Ríos Insúa, D.; La democracia electrónica, op. cit., pág. 26. 
otras aplicaciones implementadas por las AAPP5. Esta falta de adaptación lo que denota es que pese a la voluntad de progresar en cuestiones de e-democracy o e-government en base a conceptos asimilados de experiencias internacionales, lo cierto es que se asume, en muchos casos, solo una parte de estas iniciativas que fundamentan su potencial democratizador en las posibilidades de Internet. Y cuando hablamos solo de una parte nos referimos a aquellas dirigidas a mejorar los mecanismos de información y de transparencia a disposición de la ciudadanía, lo cual es plausible, pero no suficiente. Es significativo que los avances tecnológicos basados en el desarrollo de las TIC han fomentado entre otras cosas la emergencia del movimiento del open data, que ha supuesto un progreso en la idea de abrir las puertas a la información que posee el gobierno, dada la naturaleza pública de la misma ${ }^{56}$.

Con una mayor y mejor información y transparencia con el uso de las TIC se persigue que los ciudadanos ejerzan de una manera más completa, responsable y eficaz sus posibilidades de elección y disponer, asimismo, de más influencia en sus relaciones con las actuaciones públicas. Por ello Olmeda Gómez afirma que

«...el realce de la «transparencia» como valor democrático ha sido estimulado por Internet, en especial tras las filtraciones de Wikileaks. El surgimiento de la transparencia como término de moda deriva de la enorme capacidad de la red para permitir que las gentes conozcan información previamente restringida a las élites con poder ${ }^{57}$.

Por ello no es criticable, en ningún caso, el crecimiento, de la mano de las TIC, de la transparencia en el actuar público y en poner en conocimiento de los ciudadanos las actividades de los poderes públicos. Lo que censuramos es que no se potencien de una manera más profunda otras posibilidades participativas puesto que es obvio que existe un freno permanente a desarrollar de un modo más ambicioso la evolución tecnológica en el ámbito político. Y ello va en la línea de la consideración de la profesora Anduiza sobre la cuestión que tratamos. Da la sensación de que el mero uso de nuevas tecnologías se sobreentiende como un avance en sí mismo. De ahí que hablemos de un avance participativo aparente:

«Es cierto que Internet pone a nuestro alcance más información de la que nunca podremos asimilar. Pero es igualmente cierto que el ochenta por ciento de la información política que se consume en la red procede de las páginas web de medios tradicionales (prensa escrita, radio o televisión). La tecnología puede facilitar y potenciar

55 Cerrillo, A.; "Web 2.0 y la participación ciudadana en la transparencia administrativa en la sociedad de la información”, en Cotino Hueso, L. (ed.), Libertades de expresión e información en Internet y las redes sociales: ejercicio, amenazas y garantías, Servei de Publicacions de la Universitat de València, Valencia, 2011, pág. 137.

56 Villoria, M. y Cruz-Rubio, C. N.; "Gobierno abierto, transparencia y rendición de cuentas: marco conceptual”, en Villoria, M. (dir.), Forcadell, X. (coord.), Buen gobierno, transparencia e integridad institucional en el gobierno local, Tecnos, Madrid, 2016, pág. 97.

57 Olmeda Gómez, J. A.; “Gobierno electrónico, ciberpolítica y democracia”, en Cotarelo, R. y Olmeda Gómez, J. A. (coords.), La democracia del siglo XXI: política, medios de comunicación, internet y redes sociales, Centro de Estudios Políticos y Constitucionales, Madrid, 2014, pág. 4. 
procesos sociales y abre efectivamente un mundo de posibilidades. Pero no iniciará ni obligará por sí sola a cambios políticos. No constituye el factor determinante —una driving force-, sino un condicionante más. Así pues, la mala noticia es que no tenemos en Internet la panacea de nuestros males» ${ }^{58}$.

Y esta crítica puede ser tomada desde todos los ángulos. No es, solamente, una crítica a los poderes públicos y su visión acotada de las posibilidades participativas en base a las TIC. No es solo eso. El ciudadano también interioriza que participan más ciudadanos, y eso es positivo, pero hay más matices que estudiar. Porque a la hora de participar en democracia, el número es considerablemente importante debido al juego de mayorías que se produce, pero esas mayorías deben ir sustentadas en una motivación de adhesión a los principios democráticos ${ }^{59}$. Nuestro concepto de participación ciudadana desarrollada a lo largo y ancho del presente artículo es el de una participación ciudadana responsable. Es el matiz crucial y diferenciador. No pretendemos una participación ciudadana restringida, al contrario, cuantas más voces diversas colaboren en la solución de los problemas y asuntos públicos más se enriquecerá el debate y la deliberación, por supuesto. Pero esa participación masiva debe tener un halo de responsabilidad, de consciencia de lo que es participar en cualquier escenario público. No nos interesa, únicamente, la adhesión, sin más, de opiniones diversas. No se trata solo de eso. Y el problema es que con la e-democracia, con el fomento de la participación ciudadana por Internet, las estrategias que se persiguen, pese a las infinitas posibilidades de información, conducen a una agregación de pareceres sin contrastar las motivaciones ni intereses que llevan a presentar tal participación. Porque hay estudios que muestran que el «número de participantes en una acción política digital no resulta correlativo a su grado de compromiso ${ }^{60}$. Es decir, el hecho de tener de forma tan sencilla y fácil la posibilidad de participar en cuestiones políticas y de tener la posibilidad de manifestar la opinión en foros que tradicionalmente eran mucho más restringidos supone un avance exponencial en las posibilidades democráticas de cualquier organización política. Pero también conlleva que quien accede a estos nuevos escenarios no supera las dificultades previas existentes y, en consecuencia, la motivación para participar en cuestiones políticas ya no será unívoca. Morozov concluye que todas estas posibilidades tecnológicas en el ámbito político pueden provocar que la participación en Red se caracterice por actos pasivos, vinculados al entretenimiento

58 Anduiza, E.; “Panacea”, op. cit., pág. 131.

59 Castellanos Claramunt, J.; "La democracia algorítmica: inteligencia artificial, democracia y participación política” en Análisis Monográfico: Derecho Público, derechos y transparencia ante el uso de algoritmos, inteligencia artificial y big data (A. Boix Palop y L. Cotino Hueso coords.), Revista General de Derecho Administrativo, 50, Enero (2019), págs. 1-32.

60 Earl, J. y Schussman, A.; "The new site of activism: online organizations, movement entrepreneurs, and the changing location of social movementdecision-making”, en Coy, P. (ed.) Consensus Decision Making, Northern Ireland and Indigenous Movements, JAI Press, Londres, 2003. 
$y$, por tanto, inofensivos en términos de impacto político ${ }^{61}$. Se desnaturaliza desde esta perspectiva la propia participación política porque deviene en lo que Morozov denomina «slacktivism» («activismo de sillón»). Arroyo lo denomina «sofactivismo», que define como la participación en los asuntos públicos que se ejerce en el ciberespacio, a golpe de click en la pantalla, sin levantarse de la silla. Considera que los efectos de esa participación fácil pueden parecer impresionantes, y con frecuencia la fascinación de los medios de comunicación con las nuevas tecnologías los exageran ${ }^{62}$. Porque desde el ordenador de casa o desde el móvil mientras viajamos en autobús podemos adherirnos a infinidad de causas políticas que se suceden en entornos lejanos. El fin es positivo porque muestra una predisposición a colaborar o brindar nuestro apoyo a causas que consideramos justas y que se deben potenciar. Pero queda todo en eso. En un activismo desnaturalizado ${ }^{63}$. Además genera una participación fluida, pero intermitente ${ }^{64}$. Las nuevas tecnologías permiten solidarizarse con cuestiones locales de muchos otros entornos, pero no constituye el inicio de nada. Y las motivaciones son muy diversas porque no conlleva una acción real, más que la mera solidaridad virtual. Es una cuestión sobre la que reflexionar porque si el potencial de las TIC aplicado a la organización política de los ciudadanos y a la concienciación de la importancia de participar y manifestarse en las cuestiones que nos conciernen como ciudadano se circunscriben a un «me gusta» o a firmar una petición virtual el paisaje resulta desolador. Con todas las potencialidades que pueden extraerse de las TIC para aplicarlas a solucionar problemas que nos afectan a todos y el desarrollo tan enorme que conlleva la evolución tecnológica, el problema que puede producirse es que todo ello se acabaría reduciendo a adherirse de forma figurada a cuestiones que consideramos justas, pero que no nos impulsan a participar más activamente. Si se reduce todo el potencial participativo tecnológico a manifestar brevemente una opinión, la mejora democrática brillará por su ausencia. Y ello no se predica solo respecto de mostrar la solidaridad sobre cuestiones que ocurren en lugares muy lejanos. No solo ocurre en estas cuestiones. En el ámbito local también sucede. Al resultar tan «gratuito», podemos caer en la tentación de considerar que hasta ahí llega nuestro compromiso político, incluso en nuestro entorno más próximo, el local. La individualización permanente y progresiva de la sociedad, la tendencia al aislamiento propiciada, precisamente, por esta evolución tecnológica, y el hecho de producir generaciones cada vez más formadas, pero a su vez menos integradas y, en consecuencia, egoístas, supone un caldo de cultivo extraordinario para ello. También las dinámicas mayoritarias del mercado generan un individualismo radical que invita poco a la participa-

${ }^{61}$ Morozov, E.; The Net Delusion. The Dark Side of Internet Freedom, Public Affairs, Nueva York, 2011, pág. 203.

${ }^{62}$ Arroyo, L.; “¿La ciberutopía era esto? Sofactivismo, tribalismo, nueva censura y trivialización del espacio público”, op. cit., págs. 141-142.

${ }_{63}$ Castellanos Claramunt, J.; "Participación ciudadana y populismos: una contradicción no aparente”, Anales de la Cátedra Francisco Suárez 53, 2019, págs. 53-77.

${ }^{64}$ Innerarity, D.; La política en tiempos de indignación, Galaxia Gutenberg, Barcelona, 2015, pág. 219. 
ción y a compartir problemas; nuestra sociedad es muy diversa y fragmentada y alberga nuevas formas de exclusión social (edad, educación, género, etnia) que discriminan; los estilos de vida dominantes dejan poco tiempo libre para relacionarse e interactuar más allá del trabajo y la familia; y hay menos oportunidades para crear un arraigo y una continuidad a largo plazo. Así, esa participación ciudadana digital que no conlleva ningún compromiso para con los demás deviene en la participación ciudadana que conocen cada vez más las nuevas generaciones, por lo que no se profundiza en los debates, en la confrontación de pareceres y en el crecimiento personal que se produce en la doble vertiente de, por un lado, participar en los asuntos de nuestro entorno con personas igualmente afectadas por la misma situación y, por otro lado, y como consecuencia de lo anterior, la capacidad de empatizar que se desarrolla al conocer esa misma situación desde diversos prismas, atender a cómo afecta a la vida de los demás situaciones que nos afectan a nosotros de un modo diferente y que jamás nos habríamos planteado sin ese, llamémosle, feedback, que se produce como consecuencia de frecuentar entornos participativos diversos y plurales.

«Internet confirma la tendencia al tribalismo, tan animal y tan humana, que tantos antropólogos, sociólogos y filósofos han detectado desde hace cientos de años. Así, podría ser, y parece haber ya algunas pruebas de ello, que Internet estuviera favoreciendo (o al menos retratando) no una democracia más deliberativa, sino otra más polarizada, en la que resulta especialmente fácil buscar la información de los tuyos, reunirte con los tuyos, reforzarte en tus argumentos y sentirte acogido por los tuyos.

Según todos los síntomas, por tanto, el ser humano persistiría en su tenaz contradicción de los postulados de los defensores de la democracia deliberativa que suponen que el individuo, provisto de la información adecuada, está deseoso de tomar decisiones informadas, minuciosas y racionales en el sentido clásico del término «racional», tal como fue definido por los pensadores de la Ilustración europea» ${ }^{65}$.

Esa relación paradójica entre una ilimitada capacidad de encontrar información diversa y esa tendencia a reforzar los argumentos propios buscando información o posturas que se asemejen a la nuestra es otro de los matices a estudiar cuando indicábamos que para una mejor participación no basta solo con una agregación sin más de sujetos intervinientes. Para mejorar cualquier organización que se precie de ser democrática lo que se requiere es una mayor participación ciudadana, pero responsable, con acceso a la información necesaria para formar un criterio propio y con interés en conocer de los asuntos públicos. Sapere aude $e^{66}$, podría ser el lema de este nuevo impulso a la participación ciudadana apoyada en las TIC. Hay mayor facilidad con estas tecnologías de conocer en profundidad cualquier cuestión que en ningún otro momento de la Historia. Y los asuntos públicos siempre van a concernir directamente a los ciudadanos en tanto que tales. Por eso, y para su mejor desarrollo, son nece-

65 Arroyo, L.; “¿La ciberutopía era esto? Sofactivismo, tribalismo, nueva censura y trivialización del espacio público”, op. cit., págs. 146-147.

${ }^{66}$ Kant, I.; ¿Qué es la Ilustración? Alianza editorial, Madrid, 2013. 
sarios los entornos participativos diversos y plurales que no tienen por qué ser necesariamente entornos físicos, ya que ha quedado sobradamente demostrado que los entornos virtuales de decisión presentan innumerables ventajas y posibilidades, pero en cualquier caso sí se requiere una motivación, un acercamiento a la cuestión con un mínimo de perspectiva democrática, perspectiva y fundamento que consideramos que se pierde con este denominado «activismo de sillón» o con una restricción de los enfoques de la realidad. Superar ese tribalismo del que escribe Arroyo y no desnaturalizar la participación ciudadana con la mera adhesión a causas por Internet, sin mayor esfuerzo que clickar un enlace, son dos de las dificultades a las que deben enfrentarse las TIC para que la e-democracia no sea considerada un avance participativo aparente.

\section{REFLEXIONES SOBRE EL VOTO ELECTRÓNICO}

Un mantra que se repite constantemente cuando hablamos de democracia digital, e-democracia, o cualquier escenario tecnológico relacionado directamente con la democracia es la del voto electrónico. Y tiene lógica puesto que el paradigma participativo en las democracias representativas es, precisamente, la votación, el ejercicio del derecho de sufragio.

«El voto electrónico electoral no es únicamente administración electrónica —por el papel importante que tiene en el desarrollo democrático- ni únicamente democracia electrónica - por su condición de medio, y no de fin-.Y es justo en esa intersección donde se encuentra el punto común entre gobierno electrónico y democracia electrónica: el fomento de la participación ${ }^{67}$.

Durante décadas se lleva advirtiendo de que el futuro pasa por la votación electrónica, por lo que se han experimentado diversas posibilidades en numerosas votaciones, siendo los primeros en emplear estos sistemas determinados estados y condados de Estados Unidos en los años 90 del siglo pasado. Pese a las numerosas pruebas llevadas a cabo hasta la fecha, la presencia del voto por Internet en elecciones políticas y vinculantes sigue siendo reducida, por lo que solo un puñado de países, y de modo destacado Estonia, Canadá, Francia y Suiza, lo utilizan ${ }^{68}$. Y es que, por su idiosincrasia democrática, hay países especialmente proclives a introducir variantes en sus sistemas electorales, como puede ser el caso de Suiza:

${ }^{67}$ Martínez Dalmau, R.; "Constitucionalismo y democracia ante las nuevas tecnologías de la información y la comunicación”, en Noguera Fernández, A. (coord.), Crisis de la democracia y nuevas formas de participación, Tirant lo Blanch, Valencia, 2013, págs. 325-326.

${ }^{68}$ Barrat Esteve, J.; "Verificabilidad del voto por internet y su recepción en el ámbito hispano", en Guglielmi, G. J. e Ihl, O. (coords.), El voto electrónico, Centro de Estudios Políticos y Constitucionales, Madrid, 2017, pág. 176. 
«En ciertos cantones suizos, como Zúrich, Neuchatel y Ginebra, llevan experimentando con el voto electrónico desde el año 2004. Este es un recorrido considerablemente largo ya, que les ha permitido afinar aspectos defectuosos o mejorables, desarrollar nuevos mecanismos de seguridad, dar formación suficiente a la ciudadanía, etcétera. Estos mecanismos, que recibieron la mención de buena práctica por parte del programa eEuropa 2010 de la Unión Europea, arrojan resultados de uso y satisfacción por parte de la ciudadanía muy elevados» ${ }^{69}$.

Es relativamente sencillo encontrar autores que critican u observan problemas a la implementación de las votaciones electrónicas, pero lo que resulta más difícil aún es encontrar opiniones contrarias a que va a ser la forma de votación en el futuro:

«Hoy en día el voto electrónico es ya un complemento a la participación electoral tradicional muy consolidado, pero podemos aventurar que en un futuro no muy lejano las elecciones periódicas se realizarán únicamente por medios electrónicos. Los expertos no albergan dudas al respecto. La cuestión es entonces por qué no extender su uso a otras formas de participación ciudadana, como la participación directa» ${ }^{70}$.

Puede que, fundamentalmente por el ruido generado alrededor de esta cuestión, la conclusión a la que se llega es que no se tiene muy claro en qué consiste el voto electrónico. Porque no tiene una versión unívoca en el imaginario colectivo, y porque ayudará a centrar la reflexión, lo mejor será presentar primero las variantes existentes:

«La expresión «voto electrónico» designa múltiples métodos de expresión y de recuento de votos. Si nos acotamos a la tipología más empleada, tres conjuntos principales merecen ser distinguidos: el voto con máquina de recuento (una vez perforada o marcada, la papeleta vuelve a ser contabilizada por un ordenador central), el voto mediante registro directo (la papeleta se desmaterializa dando lugar a un teclado, una pantalla táctil, un lápiz (o marcador óptico) o un cursor: cada herramienta está conectada a una terminal que totaliza paulatinamente las preferencias) y el voto en línea. En este último caso, existen varios grados para incorporarlo a Internet: mediante terminales electrónicas repartidas en una circunscripción, dentro de la mesa electoral tradicional o en el domicilio del elector» ${ }^{71}$.

Podemos partir del concepto participativo que conlleva una mejora de las posibilidades de participar en los procesos electorales, como pueden ser las elecciones municipales. Así, a efectos meramente electorales, el hecho de introducir un sistema técnico nuevo en la forma de computar los votos físicamente en el lugar de votación ni suma ni resta absolutamente nada. Aquel que quisiera votar en las elecciones se dirigiría al colegio electoral que le correspondiera en el día señalado y ejercería su derecho. En la materia que nos interesa el mismo ejercicio democrático se produce

${ }^{69}$ Fundación Kaleidos; Proximidad, nuevas tecnologías y participación ciudadana en el ámbito local, op. cit., pág. 168.

70 Ibídem, pág. 167.

71 Guglielmi, G. J. e Ihl, O. (coords.); El voto electrónico, Madrid, Centro de Estudios Políticos y Constitucionales, Madrid, 2017, pág. 17. 
introduciendo un sobre en una urna que marcando en una pantalla táctil la elección dispuesta. Así que si lo que estamos desarrollando es la incidencia de las TIC y la influencia de Internet en los entornos democráticos la cuestión que va a centrar nuestro interés es una variante del voto electrónico, en concreto la del voto remoto por Internet. $\mathrm{Y}$ es aquí donde sí destacaremos las ventajas y los problemas que puede afectar a la democracia, también en el ámbito local, la implantación de este sistema.

El problema por antonomasia es el del peligro de manipulación de los resultados. Para González De la Garza «su empleo genera inseguridad, sin aportar ventajas significativas en ningún sentido relevante. Tal vez, sí la sensación de satisfacción de un prurito por adaptar las nuevas tecnologías emergentes a los sistemas electorales como condición subjetiva e ideológica de progreso $\gg^{72}$. Esta es la problemática fundamental para instaurar el voto electrónico y es que aunque se haya producido un gran avance tecnológico siempre queda la duda de qué sucedería ante una manipulación de resultados. Porque como sostiene Barrat Esteve, «el voto por Internet constituye la versión más arriesgada del voto electrónico ${ }^{73}$. La pérdida de confianza de la ciudadanía en los resultados podría conllevar un atraso de décadas de progreso democrático. Ello lleva a considerar a algunos autores que «el voto electrónico remoto se trata de una modalidad técnica de ejercicio del sufragio que, normativamente, habría de estar prohibida ${ }^{74}$. Y es que, de producirse alguna manipulación electoral, se tambalearían los cimientos de los países democráticos al existir una duda razonable, o bien pruebas manifiestas, de que el resultado electoral, en cualquiera de sus posibles escenarios, tanto local como estatal, haya sido distinto del real. Y ya no solo que sea fruto de una manipulación interesada de los resultados, también puede producirse un fallo en la contabilización de votos, en el modo de atribuirlos a los partidos políticos presentes en las elecciones, que se produzca un borrado accidental total o parcial de los votos emitidos, y eso sin contar con la ya explicada brecha digital que supondría dejar fuera del escenario electoral a un amplio conjunto de ciudadanos por motivos de pobreza y/o edad. Pero, incluso superada esta inmensa dificultad, es decir, en el caso de encontrar un sistema tan a prueba de errores que se tuviera una confianza en él tal como puede existir en el tradicional, la primera preocupación que nos plantearíamos sería la relativa a la veracidad de la identificación del elector. Para que el voto electrónico remoto sea una variante efectiva en los procesos democráticos es necesario que se despeje cualquier duda de posible suplantación en la identidad del votante.

«La sofisticación de los sistemas de autenticación o acreditación personal permite reducir considerablemente las inquietudes respecto a este foco de inseguridad, pero,

72 González De la Garza, L. M.; Voto electrónico por internet, constitución y riesgos para la democracia, op. cit., pág. 593.

${ }_{73}$ Barrat Esteve, J.; "Verificabilidad del voto por internet y su recepción en el ámbito hispano", op. cit., pág. 175 .

${ }^{74}$ González De la Garza, L. M.; Voto electrónico por internet, constitución y riesgos para la democracia, op. cit., pág. 594. 
como es evidente, cuanto más onerosa sea la identificación, más difícil será movilizar a los ciudadanos a votar con un mecanismo de este tipo» ${ }^{75}$.

Esta ya es una cuestión muy a tener en cuenta. Deberán ser extremadamente exhaustivos los métodos de identificación para que se pueda, efectivamente, ejercer el derecho a voto. La complejidad en el sistema agravará las dificultades de su implementación, pero la seguridad en esta materia resulta trascendental, por lo que necesariamente el método para llevar a cabo el proceso de voto será complicado. Pero como complicado es el relativo a la operativa bancaria para realizar determinados trámites, argumentarán sus partidarios. Para ellos el ciudadano asumiría esa carga extra de complejidad porque se trataría de una cuestión importante, sea la cuestión monetaria, como sería la cuestión democrática en cuanto al ejercicio de los deberes ciudadanos. La complejidad existirá, porque debe existir, al tratarse de una cuestión de relevancia considerable.

En todo caso, más allá de la complejidad en su desarrollo, lo que es manifiesto es que la revisión y supervisión del procedimiento del voto electrónico, especialmente el que se produce de modo remoto por Internet, sobrepasará las capacidades informáticas del ciudadano medio, tal como pone de manifiesto Barrat Esteve:

«La observación electoral en los casos de voto electrónico normalmente reposa en datos técnicos que solo pueden ser entendidos por expertos informáticos y, por lo tanto, los ciudadanos medios tendrán que tomar en consideración hasta qué punto tal metodología especializada de observación electoral es suficientemente independiente, transparente y plural» ${ }^{76}$.

Por tanto, para superar este inconveniente deberá presentarse al ciudadano un sistema lo suficientemente fiable y seguro para que se pueda equilibrar ese déficit de capacidades técnicas, que son imposibles de solventar. Por muy avanzada que vaya la tecnología, exigir unos conocimientos informáticos cada vez más exhaustivos no conlleva ninguna mejora democrática e implica un plus de exigibilidad al ciudadano que no tiene porqué cumplir. Sus deberes ciudadanos se circunscribirían, en todo caso, a la cuestión política, es decir, a asegurarse un conocimiento lo más profundo y amplio posible de la realidad política que le rodea para que lleve a cabo una participación ciudadana responsable y acorde a sus criterios propios. En ningún caso debería exigirse un añadido a ello en cuanto a solvencia informática para ejercer de revisores de un sistema complejo. He ahí, por tanto, un problema complicado de resolver para la implementación futura de estos sistemas informáticos remotos puesto que la transparencia y capacidad crítica y fiscalizadora del ciudadano, que redunda en un mejor

75 Fundación Kaleidos; Proximidad, nuevas tecnologías y participación ciudadana en el ámbito local, op. cit., pág. 166.

${ }_{76}$ Barrat Esteve, J.; "El control democrático del voto electrónico. A propósito de las novedades del sistema noruego de voto por internet”, en Noguera Fernández, A. (coord.), Crisis de la democracia y nuevas formas de participación, Tirant lo Blanch, Valencia, 2013, pág. 342. 
proceso electoral, quedará reducido a un pequeño grupo de personas con los conocimientos técnicos adecuados para comprender la complejidad del sistema electoral.

Respecto a las ventajas, yendo más allá de aspectos puramente del debate político, encontramos también elementos muy favorables a su instauración. Y es que aunque no tenga porqué sustituir, al menos por el momento, el voto electrónico en cualquiera de sus variantes al voto tradicional en papel, lo cierto es que Gálvez Muñoz pone de manifiesto la existencia de argumentos muy sólidos a su favor ${ }^{77}$. El primero es económico, puesto que las papeletas de votación conllevan un gasto en cuanto a impresión y distribución de sobres y papeletas. Gálvez Muñoz habla de más de 900 millones de papeletas por parte de la Administración en el caso de las citas electorales en España. Obviamente es un gasto excesivo puesto que la inmensa mayoría no se van a emplear. Lo que lleva al segundo argumento esgrimido, que es el medioambiental. Pese a que las papeletas se reciclen, el impacto inicial es demoledor, teniendo en cuenta que con un sistema digital, tecnológico o, en definitiva, nutrido de la virtualidad, el impacto medioambiental sería escaso. El tercer argumento es el organizativo. El Estado, sea cual sea el proceso electoral, tiene que organizar a una enorme cantidad de población y redistribuirla en mesas electorales para su votación. La cotidianeidad de las votaciones en los países democráticos nos hace perder cierta perspectiva de la complejidad organizativa que conlleva cualquier escenario electoral, sea municipal, estatal, o en cualquier otra de sus manifestaciones. El cuarto argumento es el riesgo que puede conllevar la impresión dolosa de papeletas erróneas para entorpecer el proceso democrático. Reconociendo tal posibilidad, no resiste el riesgo mucho más poderoso de intento de modificación tanto de resultados como de identificación del votante que aparece en la votación electrónica, por lo que teniendo en cuenta tal posibilidad, no parece determinante. El quinto argumento en favor de las votaciones electrónicas vendría a redundar en la complejidad organizativa puesto que considera una dificultad la adecuada distribución de papeletas en los distintos colegios electorales. Sin duda es una dificultad añadida, pero inserta en la complejidad organizativa. Eso sí, tal dificultad se desvanece en cualquier escenario de participación electoral electrónica, sea remota o presencial, precisamente por la ausencia de papeletas para ejercer el derecho de voto. El sexto argumento propuesto es la carga de trabajo que implica para las personas designadas para las funciones a desarrollar en las mesas electorales los días de votación, función que no sería necesaria en caso de voto remoto, y que se reduciría considerablemente en las votaciones electrónicas presenciales al producirse el recuento de forma automática. El séptimo y último argumento es el del peligro de la nulidad de los votos. Aquí conviene hacer una reflexión porque no necesariamente es un elemento a favor del voto electrónico. Y es que al producirse el voto con el sistema tradicional el ciudadano puede decantarse por una opción política,

77 Gálvez Muñoz, L.A.; "Sufragio y nuevas tecnologías. Hoja de ruta hacia el voto electrónico”, en Barrat Esteve, J. y Fernández Riveira, R. M. (coords.), Derecho de sufragio y participación ciudadana a través de las nuevas tecnologías, $1^{a}$ ed., Civitas, Cizur Menor Navarra, 2011, págs. 69-70. 
puede votar en blanco o puede emitir un voto nulo. Pero en el escenario de la votación electrónica el voto nulo no existe. Sería una anomalía del proceso de votación emitir un voto que no se ajusta a los parámetros de votación. Visto así se entendería como un factor corrector y positivo, es decir, aquel ciudadano que por error emite un voto nulo ejerce efectivamente su derecho a participar en las elecciones, del ámbito que sea, pero su elección no tiene el efecto que pretende. Así, pudiendo subsanar, o mejor dicho, no dando opción a que se produzca la nulidad en su votación, el ciudadano tendrá la certeza de que su elección es correcta y se computa como las demás. Ahora bien, también existe la posibilidad de que el elector emita un voto nulo conscientemente $^{78}$. Quiere participar en el proceso electoral, de ahí que no se decante por la abstención y acude al colegio electoral que le corresponde. Y ante las diversas posibilidades que se le ofrecen, decide que ninguna de ellas se ajusta a sus ideales políticos. Se sugerirá que, en ese caso, puede llevar a cabo su derecho a participar mediante un voto en blanco. Y puede ser correcto. Pero el voto en blanco no es neutro. El voto en blanco se contabiliza para realizar los repartos electorales en determinadas elecciones, por lo que si el ciudadano quiere que su participación ciudadana se reduzca al mínimo de su expresión y no tenga ninguna incidencia en el desenlace electoral en el momento del recuento de votos puede optar por emitir un voto nulo consciente. En aras de su libertad introducirá una papeleta que no se corresponda con las destinadas a tal fin, o la rayará o modificará de manera que sea nula. Da igual como lo realice, previsiblemente quiere mostrar su desacuerdo con el proceso electoral concreto en el que realiza su acción, o mostrar una disconformidad total con todas las fuerzas políticas que se presenten. Cualquier especulación es válida porque traerá causa de una libre opción del ciudadano que en el voto electrónico desaparecería. He ahí la matización al argumento de Gálvez Muñoz en cuanto a la mejora que se produce en el voto electrónico respecto del voto tradicional al eliminar la posibilidad del voto nulo. El argumento es válido siempre y cuando el fundamento de la nulidad sea desconocido por el votante. Si el elector tuvo plena consciencia de que el voto que emitía era nulo la ejecución de sistemas electorales basados en el voto electrónico deviene en una merma de las libertades del elector puesto que se desvanece una de las posibilidades que ofrecía el voto presencial mediante una papeleta electoral.

Una de las ventajas de la votación remota por Internet en el siglo XXI es la cotidianeidad de la tecnología. Comprar entradas para cualquier espectáculo, billetes de tren o avión, realizar reservas de hoteles o alquilar un coche en el destino vacacional son acciones comunes realizadas por Internet. También mucha, por no decir la inmensa mayoría, de la interacción con las entidades bancarias ya se va escorando hacia la práctica digital. Desplazarse hasta una oficina bancaria, una agencia de viajes o una estación de tren para realizar una operación que podemos realizar desde nuestro orde-

78 Reniu, J. M.; "Demasiados talones para un solo Aquiles. Los riesgos del voto electrónico”, en Cotarelo, R. y Olmeda Gómez, J. A. (coords.), La democracia del siglo XXI: (política, medios de comunicación, internet y redes sociales), Centro de Estudios Políticos y Constitucionales, Madrid, 2014, págs. 103-105. 
nador personal o a través de nuestro teléfono móvil tiene un componente de coste que antes no se percibía. Esa cotidianeidad de lo tecnológico también influye en el ámbito democrático en cuanto a que para depositar el sobre con la votación en la urna se requiere de un desplazamiento al colegio electoral, esperar una cola, y efectivamente ejercer el derecho de sufragio. Si lo extrapolamos a los ámbitos que hemos ejemplificado, como la oficina bancaria o la agencia de viajes, o el propio supermercado para realizar la compra, se observa claramente como la acción cotidiana de votar conlleva un coste que la generación más influenciada por la tecnología contemplará de forma muy clara y gráfica. De ahí que en las experiencias que se suceden en el ámbito de la votación electrónica, sobre todo en la vertiente que nos interesa especialmente, la del voto remoto, la participación tienda a aumentar:

«Un dato relevante que debemos considerar de todas las experiencias que ya se han realizado es que el uso de voto electrónico provoca un aumento significativo de la participación por parte de los ciudadanos. La reducción de costes de la participación que permiten las TIC es tal, que muchos ciudadanos se sienten más dispuestos a participar por ciertos canales electrónicos que por medios presenciales» ${ }^{79}$.

Pese a todo lo expuesto, y la validez tanto de los argumentos a favor como en contra de la instauración del voto electrónico y, en concreto, del voto electrónico remoto por Internet, lo cierto es que siguen pesando todavía más los argumentos que contradicen su implantación ${ }^{80}$. Así García Mahamut concluye que el voto por Internet «en un futuro podría constituir un buen instrumento siempre y cuando se articule un sistema fiable y seguro de votación que garantice el cumplimiento efectivo de los mandatos constitucionales y legales sobre los que se ejerce el derecho de voto en un sistema democrático» ${ }^{81}$. La transparencia del procedimiento para evitar manipulaciones, así como la garantía del secreto en la votación siguen, y seguirán, siendo el caballo de batalla para poder introducir esta innovación electoral. Y es que la sensación que subyace en toda esta cuestión es que la desconfianza por parte de todos los sectores, es decir, ciudadanía y partidos políticos, fomenta la paralización de cualquier avance en esta cuestión. De hecho la legislación al respecto prácticamente brilla por su ausencia, siendo solo reseñable la Ley 5/1990, de 15 de junio, de elecciones al

79 Fundación Kaleidos; Proximidad, nuevas tecnologías y participación ciudadana en el ámbito local, op. cit., pág. 170.

${ }^{80}$ Stonestreet, tras estudiar el proyecto piloto noruego de voto por internet considera que se ha avanzado incluyendo mecanismos que ofrecen mayor transparencia, pero concluye que, incluso peses a estos avances, deben ser «necesarias estrategias más incisivas que incrementen los esfuerzos de observación independiente con el fin de generar una mayor confianza pública en los dispositivos de votación electrónica».

Stonestreet, J.; "Electoral observation and electronic voting. Adapting traditional methodologies", Revista general de derecho público comparado, 13, 2013, pág. 3.

${ }^{81}$ García Mahamut, R.; "La participación y las nuevas tecnologías de la comunicación en España (en particular, la participación a través de Internet)”, en Pajares Montolío, E. (ed.), Nuevas dimensiones de la participación política, Tirant lo Blanch, Valencia, 2015, pág. 222. 
Parlamento Vasco, cuyo capítulo X regula el procedimiento de la votación electrónica. E, incluso, desde el aspecto jurídico trata de avanzarse en la interposición de trabas que pongan en evidencia los posibles fallos del sistema más que en plantear alternativas de mejora.

«La realidad muestra cómo desde las aproximaciones jurídicas lo que se produce es una ralentización de los procesos de adopción del voto electrónico, a menudo imponiendo nuevos requisitos jurídicos para la validación de los mismos. Un ejemplo paradigmático de ello es el trato — radicalmente distinto— dispensado al voto tradicional postal en relación a la posibilidad de implementar el voto electrónico remoto para los residentes en el extranjero» ${ }^{82}$.

Por tanto, no se atisba ni voluntad ni capacidad técnica lo suficientemente fiable para llevar a cabo, en el corto plazo, unas votaciones masivas por Internet en países como España o de su entorno. Trucco considera que «las tecnologías actuales no parecen suficientemente capaces de proporcionar a distancia la garantía de que el votante se encuentra en las condiciones más apropiadas para expresar su propio sufragio de manera completamente libre ${ }^{83}$. En definitiva parece que, por el momento, las posibilidades del voto electrónico remoto son y seguirán siendo infinitas durante un tiempo o, mejor dicho y parafraseando a Quevedo, eternas... sin principio ni fin ${ }^{84}$.

Title:

The political imbrications between citizen participation and Internet

\section{Summary:}

1. Internet and citizen participation. 2. Social networks and citizen participation. 3. E-democracy, democratic progress? 4. Reflections on electronic voting.

${ }^{82}$ Reniu, J. M.; "Demasiados talones para un solo Aquiles. Los riesgos del voto electrónico", $o p$. cit., pág. 89.

${ }_{83}$ Trucco, L.; "Il voto elettronico nella prospettiva italiana e comparata", en Pajares Montolío, E. (ed.), Nuevas dimensiones de la participación política, Tirant lo Blanch, Valencia, 2015, pág. 251.

${ }^{84}$ Quevedo, F. d.; El Buscón (edición y notas: José Ibáñez Campos), Edicomunicación, Colección Fontana, Barcelona, 1994. 


\title{
Resumen:
}

En este articulo el autor trata de mostrar las relaciones directas que se establecen entre las posibilidades que ofrece Internet y una mejora participativa. La participación ciudadana es un elemento básico en toda construcción democrática, por lo que utilizar las herramientas disponibles con el crecimiento de Internet resulta una cuestión crucial para el progreso democrático. Obviamente la relación con las redes sociales también es ampliamente comentada y estudiada, reflexionando sobre si los avances políticos que conllevan son suficientes para la mejor convivencia colectiva o si, por el contrario, se trata de una proyección de avances aparentes. Finalmente se analiza la cuestión relativa al voto electrónico como paradigma de proceso participativo online destacando sus aspectos positivos y, especialmente, los perjuicios democráticos que conlleva.

\begin{abstract}
:
In this article the author tries to show the direct relationships that are established between the possibilities offered by the Internet and a participatory improvement. Citizen participation is a basic element in any democratic construction, so using the tools available with the growth of the Internet is a crucial issue for democratic progress. Obviously the relationship with social networks is also widely discussed and studied, reflecting on whether the political advances involved are sufficient for better collective coexistence or if, on the contrary, it is a projection of apparent progress. Finally, the issue related to electronic voting is analyzed as a paradigm of online participatory process highlighting its positive aspects and, especially, the democratic damage it entails.
\end{abstract}

\section{Palabras clave:}

Participación ciudadana; participación política; democracia; Internet; Redes sociales; voto electrónico; política; e-democracia.

\section{Key words:}

Citizen participation; political participation; democracy; Internet; Social networks; electronic vote; politics; e-democracy. 